\title{
COMMENTARY
}

\section{Updates on the diagnosis and treatment of prostate cancer}

\author{
'ANNE GASNIER, MSC and ${ }^{2}$ NASSIM PARVIZI, MBBS, FRCR \\ 'Department of Physics, Royal Marsden Hospital, London, UK \\ ${ }^{2}$ Clinical Radiology, John Radcliffe Hospital, Oxford University Hospitals, Oxford, UK \\ Address correspondence to: Anne Gasnier \\ E-mail: anne.gasnier@rmh.nhs.net
}

\begin{abstract}
Prostate cancer is the second most prevalent cancer in males worldwide and the commonest cancer in males in the UK. The recent updates on the diagnosis and treatment of prostate cancer were discussed at a multidisciplinary day event organized by the British Institute of Radiology and held in London in November 2016. This day covered the use of the prostate-specific antigen biomarker and of advanced imaging techniques such as multiparametric and whole-body MRI, choline positron emission tomography/CT and gallium-labelled prostate-specific membrane antigen for the detection of prostate cancer. In addition, the results of several trials assessing the management of the disease were discussed, in particular the Prostate Cancer Intervention Versus Observation Trial and Prostate Testing for Cancer and Treatment trials which evaluated the gain of intervention vs observation, and four randomized controlled trials comparing hypofractionated and standard radiotherapy regimen. Further to this event, this commentary highlights the topical issues relating to recently published guidelines and to trials for the management of prostate cancer where these were discussed.
\end{abstract}

\section{DIAGNOSIS}

Controversies about the prostate-specific antigen test

The aim of the prostate-specific antigen (PSA) test is to reduce the mortality caused by prostate cancer by treating aggressive cancers early. Furthermore, given the increasing incidence of localized prostate cancer, radical focal therapies can treat some low-intermediate risk cancers once detected. ${ }^{1}$ However, the role of PSA as a screening test is questionable given a low specificity, which can lead to overdiagnosis and overtreatment. This implies that patients are unlikely to die from prostate cancer; nonetheless, they may suffer from the side effects of unnecessary treatment. Two large recent randomized clinical trials had conflicting results despite large numbers and high compliance in both; the European Randomized Study of Screening for Prostate Cancer trial found that PSA screening significantly reduces the mortality of prostate cancer and can be used in active surveillance but is also associated with a high risk of overdiagnosis, whereas the US Prostate, Lung, Colorectal and Ovarian (PLCO) Cancer Screening Trial concluded that there was no evidence of a reduction in mortality. ${ }^{2}$ The European Randomized Study of Screening for Prostate Cancer trial assessed 162,387 males using data from 7 international centres (1:1 randomization), which had different follow-up routines and methods as well as varied cut-off values for PSA. The ERSPC cohort had large screening intervals (4 years) for $87 \%$ of patients and a median follow-up time of 9 years. They reported that to prevent 1 death from prostate cancer, 1410 males need to be screened and 48 males treated, furthermore, suggesting that only males aged 55-69 years benefited from screening. ${ }^{3}$ The PLCO study studied 76,693 males in 10 centres with stratified randomization. The screening group received annual PSA screenings whilst controls were not actively screened. They reported death incidences of 2 and 1.7 per 10,000 person-years in the screening and control groups, respectively. The reported deaths were assigned to any of the PLCO cancers, i.e. death is less likely to have been reported as related to prostate cancer when the subject may be receiving attempted curative treatment for the disease. This may have led to no difference in mortality of the two groups after 7 years of follow-up. ${ }^{4}$ The debate surrounding PSA screening continues.

New guidelines for establishing standards of MRI in prostate cancer

Prostate Imaging Reporting and Data System 2 Multiparametric MRI (mp-MRI) provides invaluable information relating to diagnostic reliability-combining anatomical and functional data of the prostate to detect significant cancers. The Prostate Imaging Reporting and Data System v. 2 advances the previous version through offering a comprehensive overview of the role of mp-MRI including diffusion-weighted imaging and dynamic contrast enhancement. It emphasizes where documentation 
can be standardized and can match the clinical evolution of the disease. ${ }^{5}$ Furthermore, undergoing a pre-biopsy mp-MRI might allow one-quarter of patients to avoid a primary biopsy as published in the Lancet by Ahmed et $\mathrm{al}^{6}$ in 2017. This means that patients can avoid potential side effects such as pain, bleeding and infection. Furthermore, a reduction in overdiagnosis of clinically insignificant cancers can be made with subsequent targeted biopsies potentially detecting one in five of more clinically significant cancers.

\section{METastasis Reporting and Data System for Prostate Cancer}

Whole-body MRI is a new imaging technique, which has been performed thus far in only a few academic centres, to assess metastases from prostate cancer (bony and soft tissue). It is useful in monitoring responses to new drug therapies where other imaging methods fail. As such, the METastasis Reporting and Data System for Prostate Cancer is the first international expert effort to provide the burgeoning field of whole-body MRI with minimum standards of image acquisition, interpretation and reporting to improve patient care. ${ }^{7}$

\section{New imaging techniques}

Carbon-11 $\left({ }^{11} \mathrm{C}\right)$-choline positron emission tomography (PET)/ $\mathrm{CT}$ is a novel imaging biomarker for detecting metabolic changes in tumours following neoadjuvant chemotherapy and radiotherapy where PSA may not play a role or in those with high rising PSA with negative or equivocal findings on conventional imaging. ${ }^{11} \mathrm{C}$-choline PET/CT can also identify further disease such as bone metastases in high-risk patients before curative treatment or in those with equivocal findings on conventional imaging. ${ }^{8}$ Gallium-68-labelled prostate-specific membrane antigen is an emerging alternative to $\left[{ }^{11} \mathrm{C}\right]$-choline in the imaging of prostate cancer.

\section{TREATMENT}

Observation or intervention for males with localized prostate cancer?

Treatments such as prostatectomy or radiotherapy are aimed at controlling the disease but subject patients to morbidity and mortality. The Prostate Cancer Intervention Versus Observation Trial conducted in the USA concluded that radical prostatectomy offered no survival benefit compared with observation. ${ }^{9}$ However, a recent study observed that males diagnosed now with localized prostate cancer in the USA are younger, healthier and more likely to undergo prostatectomy. ${ }^{10}$

Similarly, the Prostate Testing for Cancer and Treatment trial conducted in the UK randomized patients to monitoring, prostatectomy or radiotherapy. The 10-year outcome showed that mortality resulting from prostate cancer was low for all treatments, but the incidence of disease progression and metastases was lower for surgery and radiotherapy than was for active monitoring. ${ }^{11}$

\section{Hypofractionation in radiotherapy}

Four multicentre Phase 3 randomized controlled non-inferiority trials that compared hypofractionated and conventional radiotherapy in terms of relapse-free survival have recently published their results (Table 1).

The HYpofractionated irradiation for PROstate cancer trial concluded that hypofractionation could not be regarded as the new standard of care for intermediate or high-risk prostate cancer patients. ${ }^{12}$ It reported worse acute gastrointestinal and late genitourinary toxicities for patients given hypofractionation than for those given standard fractionated radiotherapy. ${ }^{13,14}$ However, the lack of planning bladder constraints in the trial protocol was mentioned.

Three other trials (Radiation Therapy Oncology Group 0415, ${ }^{15}$ Prostate Fractionated Irradiation Trial ${ }^{16}$ and Conventional or Hypofractionated High Dose Intensity Modulated Radiotherapy for Prostate Cancer ${ }^{17}$ ) recruiting low- to high-risk patients found that hypofractionated treatments were not inferior to conventional fractionation. The toxicity between the two fractionation regimens was shown to be similar. The Conventional or Hypofractionated High Dose Intensity Modulated Radiotherapy for Prostate Cancer trial reported that the acute toxicity got worse sooner for hyprofractionated patients, but by

Table 1. Trials comparing hypofractionated and conventional prostate radiotherapy

\begin{tabular}{|c|c|c|c|c|c|c|}
\hline Trials & $\begin{array}{l}\text { Prostate } \\
\text { cancer } \\
\text { patients }\end{array}$ & Centres & Recruitment & Hypofractionation & $\begin{array}{l}\text { Conventional } \\
\text { fractionation }\end{array}$ & $\begin{array}{c}\text { Androgen } \\
\text { deprivation } \\
\text { therapy }\end{array}$ \\
\hline HYPRO & $\begin{array}{l}\text { Intermediate } \\
\text { to high risk }\end{array}$ & Netherlands & 820 & 64.6 Gy in 19 fractions & $\begin{array}{c}78 \mathrm{~Gy} \text { in } 39 \\
\text { fractions }\end{array}$ & $67 \%$ of patients \\
\hline $\begin{array}{l}\text { RTOG } \\
0415\end{array}$ & Low risk & USA & 1115 & 70 Gy in 28 fractions & $\begin{array}{c}73.8 \mathrm{~Gy} \text { in } 41 \\
\text { fractions }\end{array}$ & No \\
\hline PROFIT & $\begin{array}{l}\text { Intermediate } \\
\text { risk }\end{array}$ & $\begin{array}{c}\text { International } \\
\text { (Canada, Australia } \\
\text { and France) }\end{array}$ & 1206 & $60 \mathrm{~Gy}$ in 20 fractions & $\begin{array}{l}78 \mathrm{~Gy} \text { in } 39 \\
\text { fractions }\end{array}$ & No \\
\hline CHHiP & $\begin{array}{c}\text { Low to } \\
\text { high risk }\end{array}$ & UK & 3216 & $60 \mathrm{~Gy}$ in 20 fractions & $\begin{array}{c}74 \mathrm{~Gy} \text { in } 37 \\
\text { fractions }\end{array}$ & Most patients \\
\hline
\end{tabular}

CHHiP, Conventional or Hypofractionated High-Dose Intensity-Modulated Radiotherapy for Prostate Cancer; HYPRO, HYpofractionated irradiation for PROstate cancer; PROFIT, Prostate Fractionated Irradiation Trial; RTOG, Radiation Therapy Oncology Group. 
18 weeks, the toxicity was similar between the treatment groups. Also, the Prostate Fractionated Irradiation Trial reported a reduced late toxicity for the hypofractionated group.

\section{New treatment techniques}

The future direction for prostate cancer treatment is very exciting, with some of the most novel treatment regimens for prostate cancer including proton and carbon ion therapy, or radium-223 for prostate cancer that has spread to the bones. The Prostate Advanced Radiation Technologies Investigating Quality of Life trial is currently comparing the side effects from proton therapy and radiotherapy treatments for low- and intermediate- risk prostate cancer. ${ }^{18}$ In addition, the Japan Carbon Ion Radiation Oncology Study Group recently demonstrated a favourable outcome when using carbon ion radiotherapy from a study including 2157 patients. $^{19}$

\section{CONCLUSION}

This commentary is not exhaustive and does not include for example the well-established hormone therapy, chemotherapy or brachytherapy techniques. However, it emphasizes some of the updates in the detection and management of prostate cancer, and the need for imaging and therapeutic experts to collaborate for the delivery of the best patient care.

\section{REFERENCES}

1. Valerio M, Ahmed HU, Emberton M, Lawrentschuk N, Lazzeri M, Montironi R, et al. The role of focal therapy in the management of localised prostate cancer: a systematic review. Eur Urol 2014; 66: 732-51. doi: https://doi.org/10.1016/j. eururo.2013.05.048

2. Kim EH, Andriole GL. Prostate-specific antigen-based screening: controversy and guidelines. BMC Med 2015; 13: 61.

3. Schröder FH, Hugosson J, Roobol MJ, Tammela TL, Ciatto S, Nelen V, et al. Screening and prostate-cancer mortality in a randomized European study. $N$ Engl J Med 2009; 360: 1320-8. doi: https://doi.org/ 10.1056/nejmoa0810084

4. Andriole GL, Crawford ED, Grubb RL 3rd, Buys SS, Chia D, Church TR, et al. Mortality results from a randomized prostate-cancer screening trial. N Engl J Med 2009; 360: 1310-19. doi: https://doi.org/10.1056/ nejmoa0810696

5. Weinreb JC, Barentsz JO, Choyke PL, Cornud F, Haider MA, Macura KJ, et al. PI-RADS prostate imaging-reporting and data system: 2015, version 2. Eur Urol 2016; 69: 16-40. doi: https://doi.org/10.1016/j. eururo.2015.08.052

6. Ahmed HU, Bosaily AE, Brown LC, Gabe R, Kaplan R, Parmar MK, et al. Diagnostic accuracy of multi-parametric MRI and TRUS biopsy in prostate cancer (PROMIS): a paired validating confirmatory study. Lancet 2017; 389: 815-22. doi: https://doi.org/10.1016/ s0140-6736(16)32401-1

7. Padhani AR, Lecouvet FE, Tunariu N, Koh DM, De Keyzer F, Collins DJ, et al. Metastasis reporting and data system for prostate cancer: practical guidelines for acquisition, interpretation, and reporting of whole-body magnetic resonance imaging-based evaluations of multiorgan involvement in advanced prostate cancer. Eur Urol 2017; 71: 81-92. doi: https://doi.org/10.1016/j. eururo.2016.05.033

8. The Royal College of Radiologists. Evidencebased indications for the use of PET-CT in the United Kingdom 2016. Clin Radiol 2016; 71: e171.

9. Wilt TJ. The prostate cancer intervention versus observation trial: VA/NCI/AHRQ Cooperative Studies Program\# 407 (PIVOT): design and baseline results of a randomized controlled trial comparing radical prostatectomy with watchful waiting for men with clinically localized prostate cancer. J Natl Cancer Inst Monogr 2012; 2012: 184-90. doi: https://doi.org/10.1093/ jncimonographs/lgs041

10. Dalela D, Karabon P, Sammon J, Sood A, Löppenberg B, Trinh QD, et al. Generaliz ability of the prostate cancer intervention versus observation trial (PIVOT) results to contemporary North American men with prostate cancer. Eur Urol 2017; 71: 511-14.

11. Hamdy FC, Donovan JL, Lane JA, Mason M, Metcalfe C, Holding P, et al. 10-year outcomes after monitoring, surgery, or radiotherapy for localized prostate cancer. $N$ Engl J Med 2016; 375: 1415-24. doi: https://doi.org/ 10.1056/nejmoa1606220

12. Incrocci L, Wortel RC, Alemayehu WG, Aluwini S, Schimmel E, Krol S, et al. Hypofractionated versus conventionally fractionated radiotherapy for patients with localised prostate cancer (HYPRO): final efficacy results from a randomised, multicentre, open-label, phase 3 trial. Lancet Oncol 2016; 17: 1061-9. doi: https://doi.org/ 10.1016/s1470-2045(16)30070-5

13. Aluwini S, Pos F, Schimmel E, van Lin E, Krol S, van der Toorn PP, et al. Hypofractionated versus conventionally fractionated radiotherapy for patients with prostate cancer (HYPRO): acute toxicity results from a randomised non-inferiority phase 3 trial.
Lancet Oncol 2015; 16: 274-83. doi: https:// doi.org/10.1016/s1470-2045(14)70482-6

14. Aluwini S, Pos F, Schimmel E, Krol S, van der Toorn PP, de Jager H, et al. Hypofractionated versus conventionally fractionated radiotherapy for patients with prostate cancer (HYPRO): late toxicity results from a randomised, non-inferiority, phase 3 trial. Lancet Oncol 2016; 17: 464-74. doi: https://doi.org/ 10.1016/s1470-2045(15)00567-7

15. Lee WR, Dignam JJ, Amin MB, Bruner DW, Low D, Swanson GP, et al. Randomized phase III noninferiority study comparing two radiotherapy fractionation schedules in patients with low-risk prostate cancer. J Clin Oncol 2016; 34: 2325-32.

16. Catton CN, Lukka H, Gu CS, Martin JM, Supiot S, Chung PW, et al. Randomized trial of a hypofractionated radiation regimen for the treatment of localized prostate cancer. $J$ Clin Oncol 2017: JCO2016717397. doi: https://doi.org/10.1200/jco.2016.71.7397

17. Dearnaley D, Syndikus I, Mossop H, Khoo V, Birtle A, Bloomfield D, et al. Conventional versus hypofractionated high-dose intensitymodulated radiotherapy for prostate cancer: 5 -year outcomes of the randomised, noninferiority, phase 3 CHHiP trial. Lancet Oncol 2016; 17: 1047-60. doi: https://doi.org/ 10.1016/s1470-2045(16)30102-4

18. Massachusetts General Hospital. Proton therapy $v s$ IMRT for low or intermediate risk prostate cancer (PARTIQoL). [Accessed 15 May 2017]. Available from: https://clinicaltrials.gov/ct2/show/record/NCT01617161

19. Nomiya T, Tsuji H, Kawamura H, Ohno T, Toyama S, Shioyama Y, et al. A multiinstitutional analysis of prospective studies of carbon ion radiotherapy for prostate cancer: a report from the Japan Carbon ion Radiation Oncology Study Group (J-CROS). Radiother Oncol 2016; 121: 288-93. doi: https://doi.org/10.1016/j.radonc.2016.10.009 